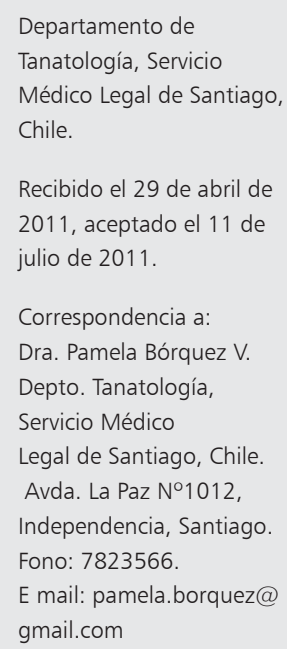

\section{Elaboración del informe médico de lesiones}

PAMELA BÓRQUEZ V.

\section{Preparation of forensic reports of injuries}

This article makes recommendations, based on good clinical practice, for the elaboration of forensic reports of injuries, required during the administration of justice. According to the new legislature in Chile, physicians must participate in the examination of victims of violent acts or accidents.

(Rev Med Chile 2012; 140: 386-389).

Key words: Forensic medicine; Legislation; Wounds and injuries.
L a confección de un buen informe de lesiones, esto es, aquel que cumple determinados víctima. La relación médico paciente, más allá de su ámbito ético -humano- profesional; implica -observado a la distancia- un procedimiento que consiste en la anamnesis, examen físico, procesamiento y análisis de la información, detección de un problema de salud o bien de un diagnóstico y un plan a seguir. Específicamente en el caso de la atención de un paciente lesionado, además de seguir dicho procedimiento para brindar un tratamiento que atienda a las necesidades clínicas del paciente, también deberá confeccionarse un informe médico de lesiones; el que para su elaboración seguirá básicamente el mismo proceso, sólo con unas pequeñas variaciones, las cuales responden al objetivo del informe.

\section{Importancia del informe médico de lesiones}

La preparación del informe es un acto médico no delegable, el cual ajustado estrictamente a la ética, implica una responsabilidad profesional relevante; siendo aquel, ejecutado por un médico general o especialista. La información allí registrada es utilizada en la investigación de delitos de lesiones dirigidas por los Fiscales. El Código Procesal Penal -en su artículo 198- solicita la confección de un informe de lesiones y la ley prescribe la posibilidad de citar a un juicio oral en calidad de testigo experto al profesional que lo haya confeccionado, con el propósito que dé testimonio aquel de manera directa, explicando -en lo posible-desde un punto de vista profesional, lo registrado.

Durante la investigación de un delito, puede ser necesario un peritaje de lesiones, el que es elaborado por un médico forense y utiliza una mayor cantidad de antecedentes (entre ellos el informe de lesiones), y cuyo objetivo es establecer y caracterizar el daño sufrido, a partir de un análisis más detallado y con mayor empleo de tiempo en el examen de los antecedentes, que aquellos de que dispone de un profesional -por ejemplo- de urgencia; lugar común donde se evacuan los informes de lesiones de común uso. Esta valoración del daño corporal, expuesta en una audiencia por un perito -en virtud del principio procesal de inmediatez- permitirá al Tribunal representarse el sufrimiento, perjuicio estético, trastorno en el entorno y en la vida de relación del afectado y por cierto, la escena en que se desarrolló el escenario que provocó tal lesión. Generalmente aquello será parte de la teoría del caso de la Fiscalía y el aporte del profesional de esta área de la salud, será entregar una porción de la historia, con el aval de la ciencia y la ética médica. Por lo anterior, es clara la importancia del informe de lesiones, ya que es el primer registro que da cuenta de la existencia de las lesiones y su naturaleza. 
El informe de lesiones, como documento médico legal, no cuenta con un formulario estandarizado a nivel nacional, sin embargo, su confección debe considerar secciones imprescindibles: origen según relato, descripción, diagnóstico, origen según la apreciación médica, incapacidad para el trabajo y pronóstico médico legal. Además, deben registrarse en el informe algunos procedimientos como son la realización del examen de alcoholemia, el manejo de evidencias y la entrega de licencia médica. Amén de lo anterior, resulta imperativo dejar clara constancia de estos elementos como de otros que tienen tanta o más relevancia. A saber: la hora, fecha y lugar y los datos del paciente como del profesional que atiende.

\section{Origen de la lesión según relato}

La anamnesis, además de recopilar la información clínica suficiente para dar un tratamiento oportuno, debe recabar antecedentes en cuanto a las circunstancias de cómo ocurrieron los hechos y su relación temporal y espacial; el mecanismo de producción de la lesión y las características del elemento con que fue provocado. Historias confusas en que el mecanismo es poco claro, extraño, imposible, excesivo o minimizado revelan la intención de ocultar información importante o bien crear una situación falsa. Así una difusa exposición en este caso, sólo confunde al tribunal que ha de apreciar la prueba y crea, lo que se conoce como "semilla de la duda razonable, ventana de una absolución".

Este fin ganancial distorsiona los hechos y puede conducir a error para lo cual se recomienda que la transcripción sea entre comillas, textual y sin juicios de valor. El profesional debe entregar su apreciación "afectivamente neutra", recordando que su rol es ilustrar solamente y no juzgar, cuestión que está entregada a un tercero, el o los Jueces.

\section{Descripción de lesiones}

Una vez terminado el examen físico, las lesiones que han sido constatadas deben comunicarse por escrito. La manera de redactar la descripción puede ir describiendo específicamente la lesión y sus características, para luego señalar su ubicación o bien puede ser de manera inversa; por ejemplo: "herida contusa de $5 \mathrm{~cm}$ de longitud en el tercio medio de la cara anterior del antebrazo derecho o bien en el tercio medio de la cara anterior del antebrazo derecho se observa una herida contusa de $5 \mathrm{~cm}$ de longitud".

Al registrar la ubicación de la lesión, se indica el segmento corporal, lado y superficie anterior o posterior. La anatomía de superficie permite ubicar de manera precisa el lugar -sin que queden dudas- donde está ubicada dicha lesión. Luego, el tipo (diagnóstico de lesión) debe ser anotado y complementado con las características necesarias de informar, como son: el número de lesiones, el color (que permite datar las lesiones: sólo los colores verde y amarillo permiten estimar datas no recientes de más de tres días de evolución), tamaño (en centímetros), la forma (las lesiones figuradas dan cuenta del objeto que las provocó), los bordes (anfractuosos o netos dan cuenta del objeto que las provocó y/o del mecanismo), presencia o ausencia de sangre, pus, costras, elementos no biológicos, entre otros.

Dejar la constancia de hallazgos negativos es información útil y su omisión puede interpretarse como falta de acuciosidad en el examen, olvido al momento de registrar o ánimo de no entregar toda la información, situación que de develarse en el juicio, deja en mal pie no sólo a quien presenta al profesional sino que a éste último, de manera irreparable.

Finalmente -en este punto- la data de la lesión, es el intervalo de tiempo que media entre el momento que se produjo la lesión y el momento que es examinado. Si bien se manejan rango de horas y días, es importante contrastar los hallazgos versus lo relatado por el paciente.

\section{Diagnóstico de la lesión}

El diagnóstico de la lesión se basa en la anamnesis, el examen físico y los conocimientos médicos; por lo que es necesario conocer las características de las lesiones según el tipo para poder identificarlas. A su vez, éstas, responden directamente al mecanismo y objeto que las produjo.

Las lesiones pueden ser ocasionadas por agentes biológicos, químicos o físicos. Dentro de estos últimos, los agentes mecánicos son los que constituyen motivo de consulta más frecuente en clínica. Subsumidos en este grupo existen tres 
grandes conjuntos de lesiones: contusas, cortantespunzantes y por proyectil de arma de fuego. En el caso de las lesiones contusas encontramos las erosiones, escoriaciones, heridas contusas, fracturas, hematomas y equimosis, el mecanismo de producción es la aplicación de energía de manera directa o indirecta a través de un trauma con un objeto romo o contra una superficie roma: suelo, pared, puño, patadas, manos, instrumentos romos. Las lesiones cortantes-punzantes presentan las siguientes posibilidades: cortantes o incisas, contuso cortantes (combinación de golpe con un objeto con filo o borde aguzado), punzantes o penetrantes y corto punzantes. Los instrumentos que las provocan pueden tener la punta aguzada y/o borde con filo. Si la herida tiene su componente externo de mayor longitud sobre la superficie corporal versus la profundidad de la lesión, estamos frente a una herida cortante. Si predomina la profundidad, (componente interno) por sobre la extensión de la herida en la superficie del cuerpo (componente externo), tenemos una herida penetrante. Las heridas corto-punzantes presentan una combinación de ambos mecanismos de producción y en estas lesiones el componente externo en mayor que las heridas penetrantes clásicas y el componente interno es mayor que el de las heridas cortantes habituales. Las lesiones por proyectiles de arma de fuego (PAF) son producto de un mecanismo contuso de alta energía que golpea en forma directa sobre el cuerpo con tres posibilidades: rozar, penetrar sin salida del PAF, penetrar con salida del PAF. Al rozar, las lesiones pueden ser escoriaciones o heridas superficiales. Al penetrar el PAF y no haber salida de éste, la lesión está constituida por la herida con forma más menos redondeada (orificio de entrada) con una trayectoria y un PAF dentro del cuerpo, que además de ser un cuerpo extraño es una evidencia. Al penetrar y haber salida de éste, existe un orificio de entrada, una trayectoria y orificio de salida. Las heridas, específicamente orificios de entrada, pueden ser en contacto firme del cañón sobre el cuerpo, en contacto sin presión del cañón sobre el cuerpo, a corta, a media y a larga distancia, lo que determina su morfología, la que además se ve afectada también según la zona anatómica lesionada, la presencia de ropas y de blancos intermedios, por ejemplo una muralla o un cinturón. En términos generales se deben describir las características del anillo de abrasión (equimótico), los bordes de las heridas, el tamaño de los orificios (heridas), la presencia o ausencia de hollín, presencia o ausencia de quemaduras, presencia o ausencia de tatuaje (que corresponden a escoriaciones). Tomar fotografías es muy útil. Todo lo anterior, en la medida que no comprometa la vitalidad del paciente.

\section{Origen de la lesión según la apreciación clínica}

La explicación médica de cómo se produjo la lesión es el resultado de la ponderación de la anamnesis y del examen físico, de la comparación de estos datos con los conocimientos médicos y de la evaluación de lo posible versus lo imposible, de los hallazgos presentes versus la ausencia de hallazgos (información negativa). Casos en que el relato habla de la caída desde un triciclo en un pre escolar de tres años (trauma de baja energía) no puede explicar un hemoperitoneo y shock hipovolémico. Se recomienda informar del siguiente modo: "La lesión descrita es compatible o no es compatible con el mecanismo de lesión relatado por el paciente".

\section{Incapacidad para el trabajo}

En el caso del informe de lesiones, esta imposibilidad para asistir a trabajar por causa de un problema de salud que requiere reposo como parte de la terapéutica, debe ser evaluada desde el punto de vista temporal y se pondera acorde a los tiempos de sanación conocidos por cada médico. Sin embargo, las lesiones y su curación no van siempre tan directamente relacionadas con la incapacidad para el trabajo, puesto que lesiones en el rostro pueden inhabilitar más allá del tiempo conocido para las lesiones. La licencia médica debe ir en concordancia al tiempo de incapacidad otorgado.

\section{Pronóstico médico legal}

Es una clasificación de gravedad de las lesiones que está al servicio de la administración de justicia e intenta armonizar criterios médicos con jurídicos. Las categorías tienen su origen en el Código Penal y son tres: leves, menos graves y graves. El tiempo en recuperarse está dado en el caso de las lesiones leves: menos de 15 días; menos graves: 
entre 15 y 30 días y graves, más de treinta días. Según las regiones comprometidas y su funcionalidad afectada, serán consideradas graves. Las que no estén en la categoría de graves serán evaluadas como menos grave y del mismo modo las que no estén en esta categoría serán catalogadas como leves (artículo 399 del Código Penal).

El parámetro principal que las rige, es la capacidad residual de la persona para reintegrarse al trabajo. Desde un punto de vista médico, no siempre se ajusta y podría excederse o haber sido limitada la ponderación inicial; sin embargo, esta clasificación es reevaluada durante la realización del peritaje de lesiones, por lo que puede mantenerse, disminuir o aumentar. Esta flexibilidad está dada por la evolución de las lesiones.

\section{Situaciones asociadas a la elaboración del informe de lesiones}

Paralelo a la atención médica y a la elaboración del informe, puede surgir según el caso, la realización de ciertas actividades que complementan al informe de lesiones: toma de muestra sanguínea para examen de alcoholemia y el levantamiento de evidencias con cadena custodia ininterrumpida. En el caso de la alcoholemia puede ser importante la toma de muestra en caso de riña o desordenes en la vía pública, ya que su uso puede ser necesario más allá de los hechos de tránsito. Las vestimentas, todo tipo de objeto usado como arma, los proyectiles de arma de fuego, las manchas, tejidos y/o fluidos biológicos; constituyen elementos que vinculan al agresor y dan cuenta de las circunstancias en que ocurrieron los hechos.

Al considerarlas dentro del estudio del caso, estos elementos se transforman en evidencias que deben ser manejadas con transparencia y cuidado para que no se extravíen ni sean dañadas o adulteradas. La cadena de custodia al ser ininterrumpida facilita esta labor. Se recomienda anotar el número único de evidencia, NUE, al informe de lesiones, para dejar registro del código y del procedimiento.

\section{Método de registro}

A continuación se mencionan una serie de recomendaciones: siempre confeccionar un original para el afectado y una copia de respaldo. Puede haber una segunda copia, la que se archiva en la ficha clínica de ser hospitalizado el paciente. La letra debe ser legible, identificación completa del paciente y del médico. El orden de las descripciones facilita la lectura del informe, por lo que se sugiere que sean de cefálico a caudal, de derecha a izquierda, de anterior a posterior, etc. Debe existir un orden fácil de colegir y repetir por un tercero en el ámbito forense.

Es dable sostener la utilización de esquemas, dibujos y/o fotografías, finalmente en las audiencias de juicio, una buena fotografía y un claro esquema facilitan al profesional su exposición.

Las lesiones se pueden agrupar cuando presentan características similares, ejemplo: múltiples escoriaciones de promedio $1 \mathrm{~cm}$ en un área de $6 \mathrm{x} 7 \mathrm{~cm}$ en tercio medio de la cara anterior del muslo derecho, de este modo evita una descripción detallada inútil. Los exámenes imagenológicos también son considerados un registro y pueden ser comentados en el informe de lesiones.

\section{Corolario}

El informe de lesiones elaborado con datos registrados legibles, completos, veraces y médicamente correctos, es un acto médico que se ajusta a la buena práctica médica y constituye un documento de calidad que da cuenta de las circunstancias y del estado inicial de las lesiones de una víctima-paciente que necesita junto a la atención clínica una adecuada administración de justicia.

\section{Referencias}

1. Teke A. Lesionología general y especial. En su: Medicina Legal \& Criminalística. Santiago, Chile: Ediciones Jurídicas de Santiago; 2004. p. 45-139.

2. Código Penal de la República de Chile. Edición oficial. Editorial Jurídica de Chile.

3. Código Procesal Penal de la República de Chile. Edición oficial. Editorial Jurídica de Chile.

4. Di Maio V, Dana S. Heridas por arma de fuego. En su: Manual de Patología Forense. Madrid, España: Ediciones Díaz Santos S.A.; 2003. p. 111-39.

5. Knight B. Examen de las heridas. En su: Medicina Forense de Simpson 2a Edición. México, D.F., México: Editorial El Manual Moderno S.A.; 1999. p. 53-66. 